\title{
A techno-economic evaluation of the impact of electric vehicles diffusion on Italian customer billing tariffs
}

\author{
Giuliano Rancilio ${ }^{1}$, Filippo Bovera ${ }^{*}$, and Maurizio Delfanti ${ }^{2}$ \\ ${ }^{1}$ Politecnico di Milano, Dipartimento di Energia, Milano \\ ${ }^{2}$ Ricerca sul Sistema Energetico, Milano
}

Keywords: electric vehicles, tariff, energy policy, regulatory toolbox, domestic charging, public charging.

Abstract. The sales of electric vehicles (EV) are recently experiencing an exponential growth. There is scientific evidence that EVs, in their lifecycle, generate a lower amount of greenhouse gases emissions and local pollution with respect to ICE ones. However, a fast EVs diffusion will increase the load on the power system in a still unclear manner. It is recognized that EV charging is a power intensive operation and that dumb charging strategies will increase security problems for grid management. This will likely happen at the end of business, when a huge quantity of EVs gets connected at the domestic socket at the same time, thus contributing to the ramp up needs from thermal generators to cope with the increasing slope in the "duck curve" at sunset. The presented model estimates the burden that different EV penetration scenarios will have on Italian power system in a short term (2025). This is evaluated in terms of energy flows and load profiles for the charging operations. A behavioural analysis of EV charging operations and a thorough investigation of Italian electricity tariff allows to calculate the economic impact of a base and a strategically regulated scenario. In the regulated scenario, featuring a regulatory toolbox to steer EVs diffusion efficiently, the impact on the power system is mitigated even in case of a larger EV penetration.

\section{Introduction}

The global sales of electric vehicles (EV) are growing exponentially in the second decade of $21^{\text {st }}$ century [1]. This process is part of the decarbonisation of the transport system, since EVs generally hold a lower carbon footprint on their lifecycle with respect to internal combustion engine (ICE) vehicles [2]. The electrification of mobility poses questions on the further burden that these new electric loads will provoke for the power system. To address this issue, vehicle-grid integration is studied at various levels [3]. The interaction with grid mainly occurs while charging the EVs. Charging activity is studied and correlated to end user behaviours [4]. The literature shows four main charging modes [5]. Domestic charging takes place at home. Charging on working place is also very diffused. Many businesses offer EV charging for their customers: commercial charging. Public charging, related to public infrastructure, is the more studied and strategically planned charging mode [6]. Also, the improvement of public infrastructure proved to be linked to the increment of EV sales [7]. Charging modes can be incentivised or hindered by the stakeholders of the system. The National Regulatory Authorities (NRAs) can play a role by modifying conveniently the tariff for the different electric users, always bearing in mind costreflectivity. ARERA, the Italian NRA, already proposed some measures to steer the EV charging by sending price signals to different users [8]. Indeed, Italian electricity tariff is based on a large portfolio of user types [9], distinguished based on the end user (domestic or other uses), on the maximum available power at the point of delivery (POD) and on the voltage level, that can be low (LV), medium (MV) and high (HV). The tariff for each type of user is based on a trinomial structure: there is a variable energy-based term $(€ / \mathrm{kWh})$, a power-based term $(€ / \mathrm{kW})$ and a fixed term $(€ / P O D)$. Generally, the power-based tariff is related to the contracted power for LV users. Contracted power is fixed at the beginning of an electric contract and it is the maximum power made available at the POD. For MV and HV users, instead, the tariff is usually related to the peak power absorbed from network in a monthly period. Therefore, it is slightly variable with loads. As introduced, the aim of a strategic planning of charging infrastructure is to decrease the impact of a further EV penetration on the power system. For instance, decreasing the evening peak can be of support [6] and can lead to the mitigation of the so-called "duck curve", the power ramp occurring at the end of the daylight hours due to increase of the load and fast decrease of the

* Corresponding author: filippo.bovera@polimi.it 
photovoltaic production [10]. Therefore, the target of the NRAs is to move a share of the load from peak to off-peak hours: in Italian tariff, off-peak is known as time band "F3".

The aim of this study is assessing the effect of the EV penetration in Italy on the power system and on the electricity tariff. Then, an essential set of measures (a regulatory toolbox) is proposed to enhance the EV penetration while mitigating the additional burden for the system. A convenient scenario with $500 \mathrm{k} \mathrm{EV}$, split in battery $(\mathrm{BEV})$ and plug-in hybrid electric vehicles (PHEV) is selected after the investigation of the institutional literature [11][12][13][14][15]. For what concerns the layout of the rest of the paper, in Section 2 we propose the methodology adopted; in Section 3 we detail the results of the study; in Section 4 we propose conclusions and possible further steps.

\section{Methodology proposed}

The study aims to describe the impact of the EV penetration on the Italian power system and on the electricity tariff income. Furthermore, it will depict the positive effects that a regulatory toolbox can have on increasing the EV penetration and benefitting of a further income while limiting its impact. Given a Base Case scenario for EV penetration at 2025, a model returns the increase in energy demand and the modification in the hourly load profile in a standard working day. A thorough investigation on the Italian electricity users and tariffs allows to correlate the energy demand for EVs to an increase in contracted power and to the amount of new dedicated PODs. These information are necessary to compute the total increase of the income from the electricity tariff in the scenario. Then, a regulatory toolbox composed by two measures aimed at increasing and steering the EV use is introduced and a Regulated Case is built-up. The effect of the adopted measures on the energy demand, the load profile and tariff income are evaluated with respect to the Base Case.

\subsection{The Base Case}

Among the many scenarios estimating the EV penetration at 2025 in Italy, a conservative scenario with $500 \mathrm{k}$ EVs has been selected for the Base Case. Of these, $70 \%$ are $\mathrm{BEV}$ and $30 \%$ are PHEV. The electric drive fraction of PHEV is $70 \%$ [16][17][1]. The characteristic of the circulating fleet are taken by the widely adopted reference [18], where the share of each car segment is considered to define the average electricity consumption (in $\mathrm{kWh} / 100 \mathrm{~km}$ ) of the fleet. That figure is updated to 2025 by applying a $10 \%$ of increase in the efficiency of the EVs, a conservative number with respect to recent estimations [19]. The average electricity consumption (ec) considered is $16.2 \mathrm{kWh} / 100 \mathrm{~km}$. The yearly mileage $(M)$ of Italian average cars is $11885 \mathrm{~km}$ as per 2019 data [20]. These data are used to compute the overall yearly energy demand $(E$, in GWh) by EVs at 2025.

$$
E=\left(N_{\mathrm{BEV}} * e+N_{\mathrm{PHEV}} * e^{*} E D\right) / 10^{6}
$$

$$
e=e c * M
$$

where $N_{\mathrm{BEV}}$ and $N_{\mathrm{PHEV}}$ are the units of $\mathrm{BEV}$ and PHEV in the scenario (350k and 150k); $e$ is the yearly energy demand for a $\mathrm{BEV}$ (in $\mathrm{kWh}$ ); $E D$ is the electric drive fraction $(70 \%)$. We assume one EV per house.

The charging behavior of EV users must be modeled to estimate the load profile from the energy demand [6][4]. To do this, the breakdown of the charging operation is hypothesized. Commercial, institutional and research sources [5][15][21][22][23][24] have been investigated to propose a realistic share of EV charging among domestic, work, B2C and public modes. In general, domestic charging is uniformly considered the most diffused, followed by charging at the working place. Public usually shows a limited share, around 5\%. The adopted breakdown is shown in Fig. 1.

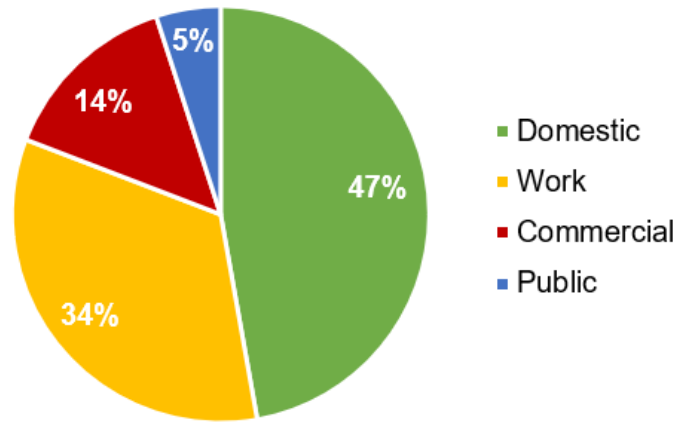

Fig. 1. Behavioural breakdown of the EV charging activity in Base Case.

$E$ is divided by 365 days in a year to find daily energy demand $\left(E_{\mathrm{d}}\right)$. Then, to have the energy demand for each charging mode $(\mathrm{m})$ in the standard working day $\left(E_{\mathrm{d}, \mathrm{m}}\right), E_{\mathrm{d}}$ is multiplied by the shares $\left(S_{\mathrm{m}}\right)$ shown in Fig. 1 .

$$
\begin{aligned}
E_{\mathrm{d}} & =E / 365, \\
E_{\mathrm{d}, \mathrm{m}} & =E_{\mathrm{d}} * S_{\mathrm{m}} .
\end{aligned}
$$

The charging modes $(\mathrm{m})$ are listed in the first column of Table 1. Then, hourly profiles for each charging mode in a working day are retrieved from literature. They are shown in Fig. 2.
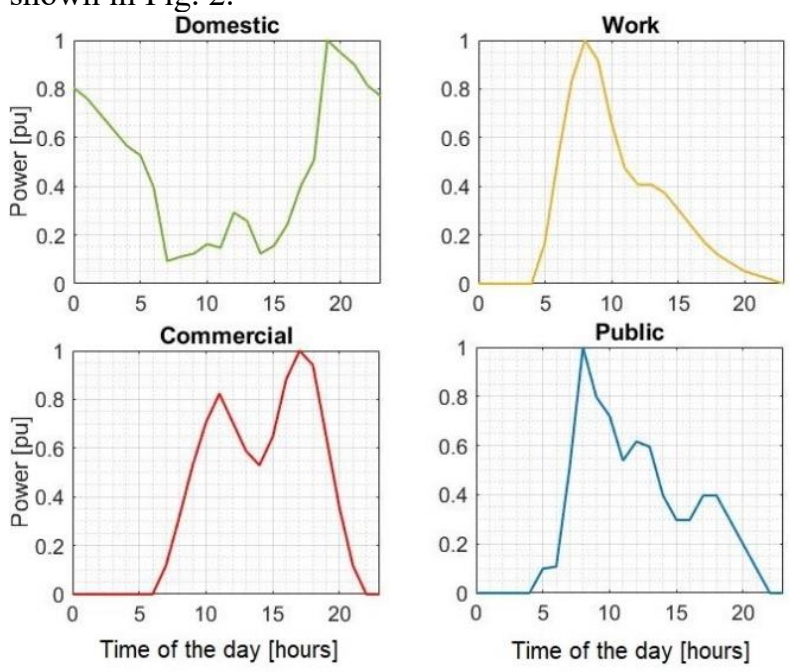

Fig. 2. Normalised hourly load profile for each charging mode. 
Domestic profile is an average between a dataset from UK [25] and the outcome of a data-driven framework for generating residential profiles [26]. Work place profile is based on a charging behavior study for the UK system operator [24]. Commercial profile depicts the possibility of charging in the parking lot of a local business (e.g. a supermarket). Therefore, it is associated to the average hourly visitors' profile for a popular business in Milan belonging to an Italian supermarket firm, retrieved from [27]. The profile obtained this way is validated via comparison with research [28]. Eventually, public charging profile is retrieved from a pattern analysis on real-world data [29]. The hourly load profiles obtained as described are rescaled so that their integral over time is equal to $E_{\mathrm{d}, \mathrm{m}}$. Their summation returns the hourly load profile for EV charging in a standard working day (whose integral in time is equal to $E_{\mathrm{d}}$.

To estimate the total income of the electricity tariff, the regulatory framework in Italy for 2019 is investigated [9]. As previously stated, electricity tariff in Italy is based on a set of electric user types identified by a code. For each type, the tariff is based on a trinomial whose terms are energy $(€ / \mathrm{kWh})$, power $(€ / \mathrm{kW} / \mathrm{y})$ and POD (€/POD/y) -based. The energy demand is allocated on the convenient types as shown by the codes in Table 1 .

Table 1. Electric user codes adopted for charging operation.

\begin{tabular}{|c|c|c|}
\hline m & Code 1 & Code 2 \\
\hline domestic & TD $(80 \%)$ & BTA2 $(20 \%)$ \\
\hline work & MTA2 $(70 \%)$ & BTA6 $(30 \%)$ \\
\hline commercial & MTA3 $(100 \%)$ & - \\
\hline public & BTVE $(95 \%)$ & MTA2 $(5 \%)$ \\
\hline
\end{tabular}

Domestic charging is mainly related to a domestic tariff (with code TD), describing those users who have a single POD for house and garage. A non-negligible share has a dedicated POD for the garage. Following the Italian regulation, it is included in the set of "other uses". The contracted power is assumed to be $3 \mathrm{~kW}$ (the associated code is BTA2). The charging on the working place is associated to the electric user of the company premises, that could be at LV (BTA6) or MV (MTA2). Commercial charging is associated to mass retailers that install charging poles available for customers in their parking lot. These premises are associated to a largescale MV user (MTA3). Public charging is represented by LV users for the vast majority. Indeed, the Italian NRA has developed the only dedicated tariff for the electric mobility [30] in LV (BTVE). A marginal share of MV public POD is considered (MTA2). It is assumed that MV charging poles are integrated in a previously existing POD (no new dedicated POD). This assumption is arbitrary, and only accepted since the quota of MV public charging is marginal (around $0.25 \%$ ).

To estimate the power-based monomial of the tariff, the variation of contracted power due to EV charging for each electric user must be conveniently estimated. As introduced before, the maximum available power at the POD for LV user is fixed in the contract. Instead, MV users pay for the peak power absorbed monthly. Therefore, the increment of power for each electric user is related to the maximum of marginal absorbed power in peak hours for each charging mode $\left(\Delta P_{\text {peak,m }}\right)$. Peak hours are the opening hours of businesses ( $8 \mathrm{AM}-8$ PM) for commercial charging mode, while it is the morning or the evening peak for the other users [31]. Then, the increment in contracted power for each tariff $\mathrm{n}\left(\Delta P_{\mathrm{n}}\right)$ is computed by taking in account the share of each tariff reported in the second and third columns of Table $1\left(S_{\mathrm{n}}\right)$.

$$
\Delta P_{\mathrm{n}}=\Delta P_{\text {peak,m }} * S_{\mathrm{n}} .
$$

As described, the variation in power for a domestic user (in LV) is associated to an enhanced contracted power of a fixed step. In Italy, most of domestic users have a contracted power of $3 \mathrm{~kW}$. Another share of users have $4.5 \mathrm{~kW}$ [32]. Therefore, we can estimate a share of users increasing their contracted power of $1.5 \mathrm{~kW}$ coherent with $\Delta P_{\mathrm{TD}}$.

For public charging, the increase in contracted power depends on the utilization rate $(u)$ of the charging poles.

$$
u=E * S_{\text {public }} /\left(P_{\mathrm{p}} * 8760\right)
$$

where $P_{\mathrm{p}}$ is the contracted power of the poles and 8760 are the hours in a year. We assume $\mathrm{u}=1.6 \%$ based on data released by the Italian NRA [33]. We are aware that research hypothesize value around $4-5 \%$ in a mature market [34]. Equation (6) can be used to estimate contracted power for public charging. The number of new POD is estimated by assuming an average of $14 \mathrm{~kW}$ per POD.

These data and assumptions are used to estimate the total increment in electricity tariff income related to EV charging at 2025. To compute the total energy-related costs for EV charging, the data reported in Table 2, mainly referred to 2018 (latest year available) are assumed.

Table 2. Additional data for energy costs.

\begin{tabular}{|c|c|c|c|}
\hline Data & Unit & Value & Source \\
\hline $\begin{array}{c}\text { Energy cost } \\
\text { LV }\end{array}$ & $€ / \mathrm{kWh}$ & 0.102 & {$[35]$} \\
\hline $\begin{array}{c}\text { Energy cost } \\
\text { MV and } \\
\text { public }\end{array}$ & $€ / \mathrm{kWh}$ & 0.075 & {$[36]$} \\
\hline Taxes & $\%$ & $\begin{array}{c}22 \%(10 \% \text { for } \\
\text { TD residential })\end{array}$ & {$[9]$} \\
\hline
\end{tabular}

\subsection{The Regulated Case}

A regulatory toolbox is introduced to estimate the potential benefits of a Regulated Case with respect to impact on power system and tariff income with a larger EV penetration. We discuss two main measures, reported in Table 3 . 
Table 3. Regulatory toolbox description.

\begin{tabular}{|c|c|c|c|}
\hline$\#$ & $\begin{array}{c}\text { Measure } \\
\text { name }\end{array}$ & Description & Effect \\
\hline 1 & $\begin{array}{c}\text { TD off-peak } \\
\text { power } \\
\text { increment }\end{array}$ & $\begin{array}{c}\text { TD user can } \\
\text { absorb up to } 6 \mathrm{~kW} \\
\text { in off-peak }\end{array}$ & $\begin{array}{c}\text { Flattening domestic } \\
\text { charging load profile } \\
\text { (evening peak) }\end{array}$ \\
\hline 2 & $\begin{array}{c}\text { LV public } \\
\text { charging } \\
\text { tariff cut }\end{array}$ & $\begin{array}{c}\text { Tariff is decreased } \\
\text { to be equal to TD } \\
\text { (non-residential) }\end{array}$ & $\begin{array}{c}\text { The sensible decrease } \\
\text { in cost of public } \\
\text { charging increases the } \\
\text { EV penetration } \\
(+20 \%)\end{array}$ \\
\hline
\end{tabular}

These measures have been selected to show the impact of two very different actions. Measure \#1 allows the TD user to absorb from grid a power up to $6 \mathrm{~kW}$ during off-peak (F3), without a further cost for contracted power increment. This is acting on the largest share of EV charging. The aim is to decrease the impact on the system of the peak shown in Fig. 2 for domestic charging (7-9 PM). This measure is discussed by a document of the Italian NRA. Measure \#2 proposes to largely decrease the value of the tariff for public charging poles in LV (BTVE) from the value in 2019 (around $0.18 € / \mathrm{kWh}$ ). It is well known that the conditions of the public charging infrastructure are related to EV sales [37][38][39], even if public charging holds a minor share. Therefore, a measure largely decreasing the cost of public charging (indeed, $60 \%$ of overall costs is tariff-related [30]) is foreseen to enhance the EV penetration with a limited negative impact on tariff income. We target an increase in EV penetration of $20 \%$, passing from a scenario with $500 \mathrm{k} \mathrm{EV}$ in the Base Case to $600 \mathrm{k} \mathrm{EV}$ in the Regulated Case. It is important to highlight that measure \#2 is not necessarily cost-reflective: it is an incentive for accelerating EV diffusion.

The breakdown of the charging activity is assumed to change due to these measures: the public charging doubles at the expenses of working and commercial charging modes.

Domestic charging share keeps constant, while its load profile is foreseen to change. We assume $20 \%$ participation of domestic users to measure \#1. It is known that the participation rate to demand response by domestic users depends on environmental conditions and economic incentives [40][41]. The benefits foreseen in this case are related to the cost avoided for increment in contracted power (the share of domestic users increasing TD power in the Regulated Case is 0) and to the possibility of selecting a time-of-use electricity contract by the retailer (whose cost is outside the focus of this study). Therefore, the load profile for domestic charging is modified by lowering of $20 \%$ the peak and shoulder hours demand and to increase coherently offpeak demand. For Regulated Case, load profile and tariff income are estimated as described for Base Case.

\subsection{Techno-economic evaluation}

The load profiles and the tariff incomes are compared between Base and Regulated case. The intention is verifying the benefit of introducing a regulatory toolbox for fostering the diffusion of EV and steering their impact on the power system.

\section{Results}

The load profile of the EV charging operation in a standard working day is shown in Fig. 3. It represents the variation of the average hourly load profile of the system at 2025 in the Base and Regulated cases. As can be seen, the increase in EV penetration generally lifts the hourly load profile. Two peaks can be seen in the Base profile: a morning peak around 9 AM $(160 \mathrm{MW})$ and an evening peak at $8 \mathrm{PM}(140 \mathrm{MW})$. It is well known that the evening peak increases the burden for the systems and enhances the so-called duck curve [10]. The Regulated profile presents a sensible increment in the morning peak (195 MW), given by the larger EV penetration. Instead, the evening peak is kept constant. This is obtained by the demand response to measure \#1. Indeed, the home charging activity increases at $11 \mathrm{PM}$ while entering in off-peak ("F3" time band of Italian regulation).

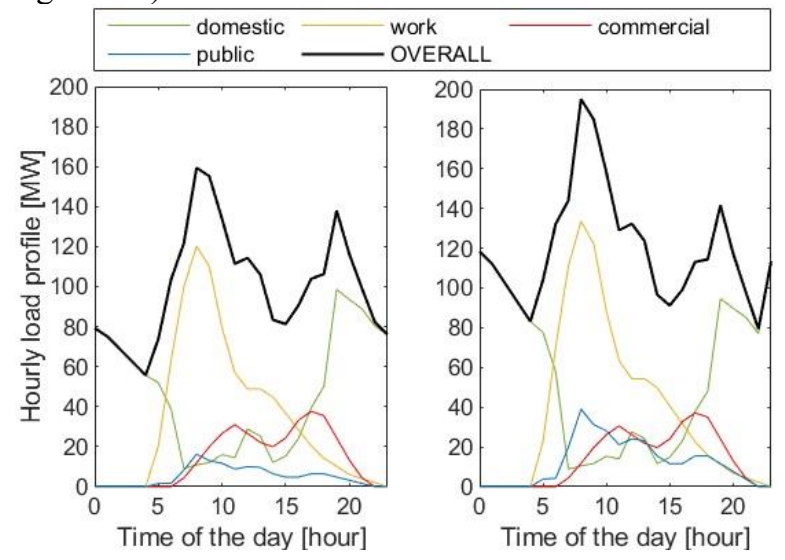

Fig. 3. The hourly load profile for Base (to the left) and Regulated (to the right) case.

The cost of charging operation is estimated for both the cases and for each user. Since the focus of the study is on the energy policies that an NRA can propose and on the effect on tariff income, the electricity tariff income in the two scenarios is reported in Fig. 4. The relative contribution of the implementation of the toolbox and of the resulting increase in EV penetration are shown. The overall tariff income passes from 74 to $81 \mathrm{M} €$ switching from Base to Regulated case. The income is broken down by the relevant electric users in Fig. 5. As can be seen, all but public charging contributions increase passing to Regulated case. This is because the large increase in the share of public charging is obtained by decreasing the energy-based component of BTVE from 0.18 to $0.06 € / \mathrm{kWh}$ (equal to the nonresidential TD). The total cost of energy for EV charging is presented in Fig. 6 for Base Case. It includes the tariff, the energy cost and the taxes. Domestic charging is the most convenient (less than $0.18 € / \mathrm{kWh}$ ), but only in case of single POD for the house and the garage. In case of separate POD (BTA2 tariff), the cost is doubled ( 0.35 $€ / \mathrm{kWh})$. Work and commercial charging modes are averagely below $0.20 € / \mathrm{kWh}$. This can be an important indication for businesses, that often give for free their electricity to employees or customers. Public charging, represented mainly by BTVE code, has a total cost of energy around $0.30 € / \mathrm{kWh}$. Charging on the public 
infrastructure at a market price results largely uneconomic. It is important to notice that this price does not include the charging point operator's surplus. Ultimately, the large cost of public charging can be detrimental for EV sales [7]. Therefore, the benefit of adopting the regulatory toolbox is clear by investigating the energy costs of Regulated Case presented in Fig. 7. The main difference with respect to Fig. 6 is the overall cost of energy for BTVE user: it shrinks from 0.31 to $0.16 € / \mathrm{kWh}$

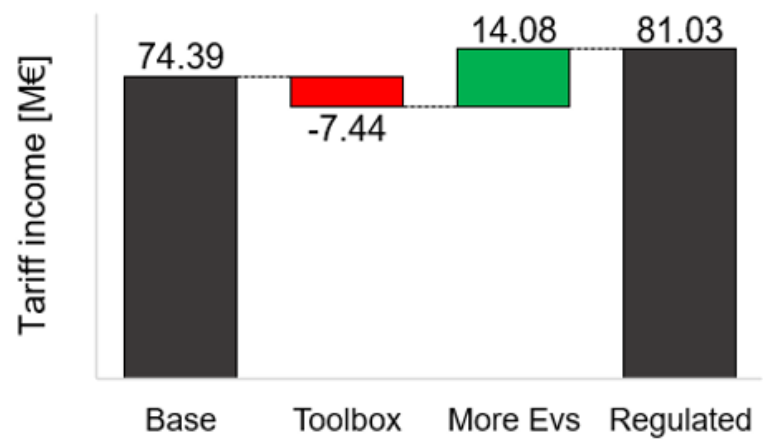

Fig. 4. The electricity tariff income to 2025 for Base and Regulated cases. In red, the decrease of income related to the introduction of the toolbox. In green, the benefit of the increase in $\mathrm{EV}$ penetration.
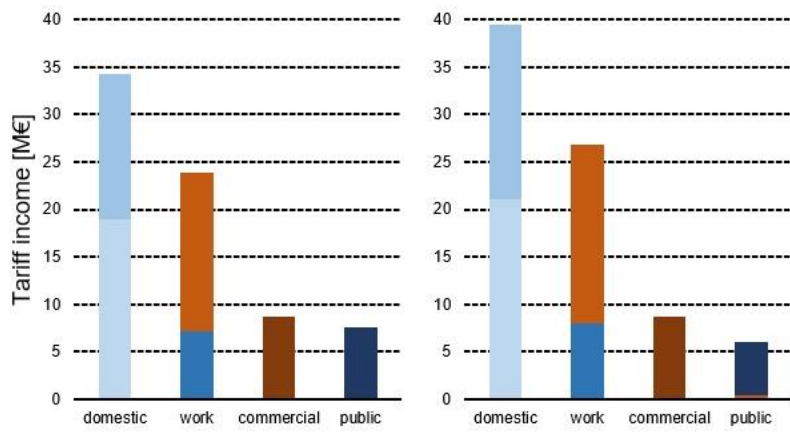

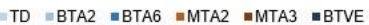

TD $=$ BTA2 $\backsim B T A 6 \quad \backsim M T A 2 \quad=M T A 3 \quad=B T V E$

Fig. 5. The electricity tariff income for each charging mode in the Base Case (to the left) and in the Regulated Case (to the right). Each column is split among the different electric users associated to a charging mode.

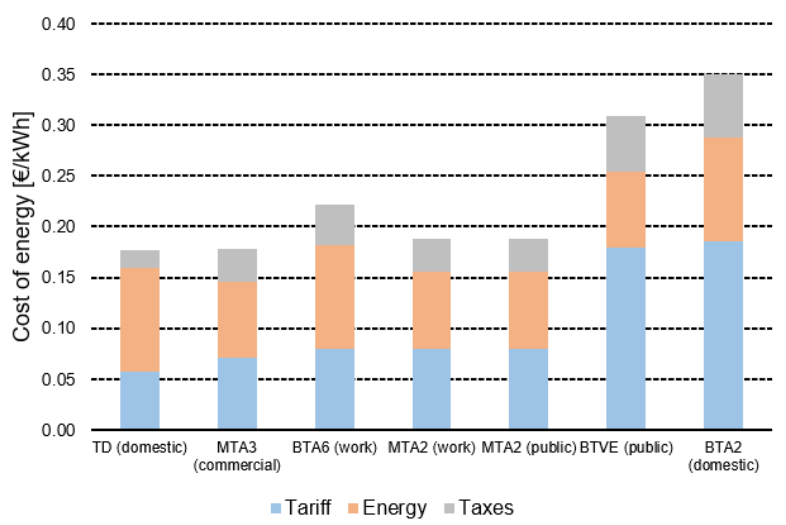

Fig. 6. The overall cost of electricity for each user in the Base Case.

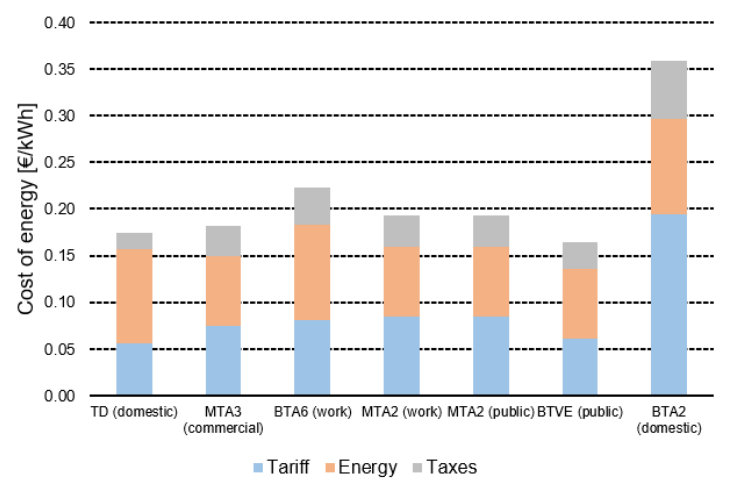

Fig. 7. The overall cost of electricity for each user in the Regulated Case.

\section{Conclusions}

The study presented a detailed analysis of the impact on electricity tariff of different level of EV penetration, considering realistic scenarios for Italy at 2025.

An essential regulatory toolbox is proposed for fostering the $\mathrm{EV}$ diffusion without exacerbate the impact on the power system. In particular, an increase of $20 \%$ of the EV fleet is targeted. The regulatory toolbox is there to decrease the overall cost of EV charging and so to push the differential in the variable costs with respect to an ICE vehicle (thus incrementing the probability of a larger EV diffusion [42]). Furthermore, the measures taken aim to decrease the evening peak demand from EV via a rudimental demand response scheme (with targeted $20 \%$ participation by domestic users owning an EV). Overall, the tariff income increases of around $10 \%$ as the cost of charging decreases passing from a basic scenario to a strategically regulated one. The limitations of this study include the adoption of assumptions to get to a whole-of-tariff result. These assumptions are based on expert advices and on a wide literature review. Further studies could include a sensitivity analysis on the main assumptions. For example, the developed mode can be used to assess the minimum EV penetration for keeping constant the tariff income after the adoption of a regulatory toolbox. Besides, a more detailed regulatory toolbox could be developed to include measures to solve other issues that this study made evident. For instance, a regulatory measure could decrease the very high cost of electricity for the domestic charging of users with a separate POD for the car garage. Moreover, a dedicated measure could be set to encourage fast charging at a convenient price beneath new dedicated MV PODs on the highways.

Giuliano Rancilio is partially funded in his research activities by the Enel Foundation.

\section{References}

1. IEA, “Global EV Outlook 2019," Paris, 2019.

2. RSE, "Auto elettrica e de-carbonizzazione: facciamo chiarezza," Milan, 2019.

3. M. Wolinetz, J. Axsen, J. Peters, and C. Crawford, "Simulating the value of electric-vehicle-grid integration using a behaviourally realistic model," Nat. Energy, vol. 3, no. 2, pp. 132-139, 2018, doi: 
10.1038/s41560-017-0077-9.

4. J. Quirós-Tortós, L. F. Ochoa, and B. Lees, “A statistical analysis of EV charging behavior in the UK," in 2015 IEEE PES Innovative Smart Grid Technologies Latin America (ISGT LATAM), Oct. 2015, pp. 445-449, doi: 10.1109/ISGT-

LA.2015.7381196.

5. T\&E, "Recharge EU," Brussels, 2020.

6. J. R. Helmus, J. C. Spoelstra, N. Refa, M. Lees, and R. [van den Hoed], "Assessment of public charging infrastructure push and pull rollout strategies: The case of the Netherlands," Energy Policy, vol. 121, pp. 35-47, 2018, doi: https://doi.org/10.1016/j.enpol.2018.06.011.

7. P. Z. Lévay, Y. Drossinos, and C. Thiel, "The effect of fiscal incentives on market penetration of electric vehicles: A pairwise comparison of total cost of ownership," Energy Policy, vol. 105, pp. 524-533, 2017, doi:

https://doi.org/10.1016/j.enpol.2017.02.054.

8. ARERA, "Documento per la consultazione 318/2019/R/eel," Milan, 2019

9. ARERA, "Delibera 23 dicembre 2015 654/2015/R/eel," Milan, 2015.

10. L. F. Bossmann, Tobias, Paul Barberi, "Effect of high shares of renewables on power systems," METIS Stud., 2018

11. MISE and MATTM, "Strategia elettrica nazionale," Rome, 2017.

12. MATTM, MISE, MIT, and RSE, "Elementi per una roadmap della mobilità sostenibile," Milan, 2017.

13. Terna and Snam, "Documento di Descrizione degli Scenari," Rome, 2019.

14. Ambrosetti and Enel, "E-mobility revolution," Rome.

15. Energy \& Strategy Group, "Smart Mobility Report 2019," Milan, 2019.

16. P. Plötz, S. Funke, and P. Jochem, "Real-world fuel economy and $\mathrm{CO} 2$ emissions of plug-in hybrid electric vehicles," Karlsruhe, 2015.

17. R. Sioshansi, R. Fagiani, and V. Marano, "Cost and emissions impacts of plug-in hybrid vehicles on the Ohio power system," Energy Policy, vol. 38, no. 11, pp. 6703-6712, 2010, doi: https://doi.org/10.1016/j.enpol.2010.06.040.

18. R. Loisel, G. Pasaoglu, and C. Thiel, "Large-scale deployment of electric vehicles in Germany by 2030: An analysis of grid-to-vehicle and vehicle-togrid concepts," Energy Policy, vol. 65, pp. 432-443, 2014, doi:

https://doi.org/10.1016/j.enpol.2013.10.029.

19. D. Pareek, "Performance \& Efficiency Improvement of Electric Vehicle Power Train," in NuGen Summit, Nov. 2019, doi: https://doi.org/10.4271/2019-282483.

20. UnipolSai, "Osservatorio UnipolSai sulle abitudini di guida in Italia," Bologna, 2019.

21. C. Weiller, "Plug-in hybrid electric vehicle impacts on hourly electricity demand in the United States," Energy Policy, vol. 39, no. 6, pp. 3766-3778, 2011, doi: https://doi.org/10.1016/j.enpol.2011.04.005.

22. T. Gnann, A.-L. Klingler, and M. Kühnbach, "The load shift potential of plug-in electric vehicles with different amounts of charging infrastructure," $J$. Power Sources, vol. 390, pp. 20-29, 2018, doi: https://doi.org/10.1016/j.jpowsour.2018.04.029.

23. T\&E, "Roll-out of public EV charging infrastructure in the EU," Brussels, 2018.

24. Element Energy Limited, "Electric Vehicle Charging Behaviour Study," Cambridge, 2019.
25. Northern Powergrid, "CLNR Customer Trials - A guide to the load \& generation profile datasets," Newcastle upon Tyne, 2014.

26. Z. Yi and D. Scoffield, "A Data-Driven Framework for Residential Electric Vehicle Charging Load Profile Generation," in 2018 IEEE Transportation Electrification Conference and Expo (ITEC), Jun. 2018, pp. 519-524, doi:

10.1109/ITEC.2018.8450228.

27. "Google," 2020. https://www.google.com/ (accessed May 26, 2020).

28. M. S. Islam and N. Mithulananthan, "Daily EV load profile of an EV charging station at business premises," in 2016 IEEE Innovative Smart Grid Technologies - Asia (ISGT-Asia), Nov. 2016, pp. 787-792, doi: 10.1109/ISGT-Asia.2016.7796485.

29. R. R. Desai, R. B. Chen, and W. Armington, "A Pattern Analysis of Daily Electric Vehicle Charging Profiles: Operational Efficiency and Environmental Impacts," J. Adv. Transp., vol. 2018, p. 6930932, 2018, doi: 10.1155/2018/6930932.

30. ARERA, "Scheda tecnica - Prezzi dei servizi di ricarica per veicoli elettrici e sistema tariffario dell'energia elettrica," Milan, 2018.

31. J. Torriti, "The Risk of Residential Peak Electricity Demand: A Comparison of Five European Countries," Energies, vol. 10, no. 3, 2017, doi: 10.3390/en10030385.

32. ARERA, "Relazione annuale 2019," Milan, 2019.

33. ARERA, "Deliberazione 9 aprile 2019 126/2019/R/eel," Milan, 2019.

34. R. Wolbertus, R. van den Hoed, and S. Maase, "Benchmarking Charging Infrastructure Utilization," World Electr. Veh. J., vol. 8, no. 4, pp. 754-771, Dec. 2016, doi: 10.3390/wevj8040754.

35. ARERA, "Andamento del prezzo dell'energia elettrica per il consumatore domestico tipo in maggior tutela," Milan, 2019.

36. ARERA, "Prezzi finali dell'energia elettrica per i consumatori industriali - UE e area Euro," Milan, 2019.

37. Y. A. Alhazmi and M. M. A. Salama, "A Statistical Approach to Estimate the Correlation between Charging Station Availability and Plug - In Electric Vehicle Sales in Canada," in Proceedings of the 2015International Conference on Operations Excellence and Service Engineering, 2015.

38. S. Hardman et al., "A review of consumer preferences of and interactions with electric vehicle charging infrastructure," Transp. Res. Part D Transp. Environ., vol. 62, pp. 508-523, 2018, doi: https://doi.org/10.1016/j.trd.2018.04.002.

39. G. Harrison and C. Thiel, "An exploratory policy analysis of electric vehicle sales competition and sensitivity to infrastructure in Europe," Technol. Forecast. Soc. Change, vol. 114, pp. 165-178, 2017, doi: https://doi.org/10.1016/j.techfore.2016.08.007.

40. C. Silva, P. Faria, and Z. Vale, "Rating the Participation in Demand Response Programs for a More Accurate Aggregated Schedule of Consumers after Enrolment Period," Electronics, vol. 9, no. 2, p. 349, Feb. 2020, doi: 10.3390/electronics9020349.

41. D. Torstensson and F. Wallin, "Potential and Barriers for Demand Response at Household Customers," Energy Procedia, vol. 75, pp. 11891196, 2015, doi: https://doi.org/10.1016/j.egypro.2015.07.570.

42. BCG, "Who Will Drive Electric Cars to the Tipping Point?," Boston, 2020. 